\title{
APRESENTAÇÃO
}

PRESENTATION

\section{PATRIMÔNIO AFRO-RELIGIOSO: ACERVOS, PRESERVAÇÃO E FONTE DE CONHECIMENTO}

\author{
Luiz Assunção \\ (UFRN, Brasil) \\ Stefania Capone \\ (CNRS, CéSor/EHESS, França) \\ Mariana Ramos de Morais \\ (CéSor/EHESS, França)
}

Escrevemos estas notas introdutórias em meio a uma pandemia inimaginável quando propusemos o dossiê Patrimônio Afro-Religioso: acervos, preservação e fonte de conhecimento. Os efeitos da Covid-19 por todo o planeta ainda são imensuráveis. No Brasil, a crise sanitária causada pela dificuldade em conter o avanço da doença somou-se à crise político-econômica já anunciada desde o início do mandato do presidente Jair Bolsonaro, resultando em um desgoverno no que tange às ações voltadas para o combate à doença que, até o fim de julho de 2020, havia matado mais de 92 mil brasileiros ${ }^{1}$. Se as projeções sobre os efeitos da pandemia seguem incertas, os dados do presente demonstram como ela tem exacerbado as desigualdades em nossa sociedade. A grande vítima dessa doença é a população mais vulnerável socialmente que, no Brasil, tem cor: negra. É dessa parcela da população, majoritária no país, que advêm as práticas religiosas que compõem o que nomeamos "patrimônio afro-religioso", cujo prefixo "afro" remete às recorrentes reivindicações de uma herança africana por parte de seus detentores.

Tratam-se de práticas que não se adequavam aos moldes estabelecidos pela política patrimonial brasileira, de seu início nos anos 1930 até o começo da década de 1980, motivo pelo qual elas não eram reconhecidas enquanto patrimônio de uma nação, a brasileira, tão devedora de diferentes povos africanos em sua constituição. O tombamento do terreiro de candomblé da Casa Branca, em Salvador, na Bahia, em 1984, é um marco da lenta mudança operada nessa política pública que, ao considerar a dimensão imaterial dos bens culturais, ampliou, ainda que timidamente, a presença de elementos referentes à cultura negra no rol dos patrimônios nacionais (CAPONE; MORAIS, 2015) ${ }^{2}$. Essa mudança é observada, especialmente, a partir dos anos 2000, quando, no âmbito federal, é estabelecida uma normativa que institui o registro dos bens culturais de natureza imaterial, o Decreto 3.551/2000, incidindo nas ações do órgão gestor do patrimônio, o Instituto Histórico e Artístico Nacional (IPHAN), então vinculado ao Ministério da Cultura. Vale 
lembrar que essa mudança estava em consonância com as prerrogativas da Unesco acerca do patrimônio cultural ${ }^{3}$.

Naquele mesmo momento, havia uma intensificação do debate sobre o combate ao racismo, na esfera global e também nacional, reverberando na instituição, em 2003, da Política Nacional de Promoção da Igualdade Racial e da Secretaria de Políticas de Promoção da Igualdade Racial (Seppir), que tinha status de ministério. Dentre as ações para combater o racismo e a desigualdade racial constavam medidas voltadas para as religiões afro-brasileiras. No contexto dessa política pública, tais religiões eram consideradas repositórios da memória africana e, portanto, deveriam ser preservadas por guardarem parte da cultura referente à população negra. Patrimonializar era um dos caminhos previstos pelo poder público no intento de proteger essas religiões (MORAIS, 2018).

Esse caminho também era acionado pelos próprios adeptos para garantir a continuidade de suas práticas frente às adversidades que enfrentavam, tais como: o interesse do mercado imobiliário em terrenos que ocupavam, as crises internas devido à sucessão da sacerdotisa ou do sacerdote principal e os crescentes ataques advindos de grupos evangélicos. Além disso, eles também criaram maneiras próprias de patrimonializar suas práticas. A chancela do poder público, claro, mantém sua importância por ter força de lei. Contudo, iniciativas dos adeptos também ganham relevo em um contexto de crescente valorização da memória, de tentativas de se recompor um passado. Assim, observa-se, por exemplo, a criação de museus em terreiros e a busca pela recuperação de acervos documentais de suas lideranças. Trata-se de uma cena complexa que expõe as controvérsias e as disputas do campo afro-religioso e também demonstra como interesses de grupos específicos podem ser reivindicados em demandas coletivas, ainda que sob outra roupagem.

Em 2018, durante o Seminário Internacional Patrimônio e Religiões Afro-brasileiras, realizado em Natal, na Universidade Federal do Rio Grande do Norte, essa cena sobressaiu nos debates. O encontro foi coordenado por Luiz Assunção e teve a participação de Stefania Capone e Mariana Ramos de Morais. Agora, juntos, apresentamos aos leitores este dossiê pensado a partir daquela experiência, que, por sua vez, foi motivada por um caso particular. O referido seminário tinha como objetivo discutir com a comunidade acadêmica e com o povo de santo de Natal questões relativas à patrimonialização das religiões afro-brasileiras. Esse era um tema, em certa medida, novo para a comunidade local, que não dispunha de nenhum terreiro reconhecido como patrimônio cultural seja na esfera municipal, estadual ou federal. No entanto, a possibilidade de se patrimonializar uma das casas da cidade avivava o interesse dos adeptos pelo tema.

O terreiro em questão era o Centro Humilde de Caridade São Lázaro, cujo terreno passou a ser alvo de disputa judicial após a morte de seu fundador, o babalorixá José Barroso dos Santos. A patrimonialização 
seria, para uma das partes interessadas no terreno, uma maneira de preservar o legado de seu Barroso. A imagem que ilustra a capa desta edição da Vivência - Revista de Antropologia UFRN é, inclusive, a representação do caboclo Taitumba, seu protetor e mentor. Ela é a reprodução de um quadro, pertencente ao acervo do Centro Humilde de Caridade São Lázaro, que foi adquirido pelo babalorixá em uma de suas muitas viagens a Salvador. Ele era iniciado no candomblé queto, mas também mantinha em sua prática ritualística o culto às entidades espirituais da umbanda e da jurema. Filho de Obaluaiê, recebia o Caboclo Taitumba em suas sessões de trabalho e de cura. Ao escolhermos essa imagem para abrir esta edição, rendemos homenagem a seu Barroso, ao mesmo tempo em que destacamos, sob a invocação de Taitumba, essa entidade tão emblemática das religiões afro-brasileiras: o caboclo.

O caboclo é considerado o "dono da terra" por representar aqueles que já habitavam o território batizado como Brasil antes da chegada dos europeus e dos africanos. Ele figura em diferentes religiões afro-brasileiras, embora possa ocupar posições distintas em cada uma delas, como pode ser observado a partir dos três exemplos a seguir. Na umbanda, o caboclo ganha feições do indígena moldado nas letras do romantismo. $\mathrm{E}$, juntamente com entidades que representam a herança europeia e a africana, ele compõe a tríade que faz da umbanda a religião dita genuinamente brasileira. Já na jurema, ele configura um elemento chave que busca autenticar a forte marca dos povos indígenas em sua constituição (ASSUNCÃO, 2006). No candomblé, por seu turno, ele pode ser uma espécie de persona non grata a depender da modalidade de culto. Nos candomblés que afirmam seu vínculo a uma tradição banta, considerados por parte da literatura mais sujeitos a influências de outras culturas que não as africanas, sua presença é explicitada. Por outro lado, nos candomblés que reclamam pertencimento a uma tradição iorubá e que adotam medidas que visam a reafricanização de suas práticas, podem mesmo não o incluir em sua ritualística (CAPONE, 2018). Ele, o caboclo, poderia colocar em xeque a suposta "pureza" ritual que reivindicam para si, já que evidencia a "mistura".

De fato, a "mistura" é uma característica própria das religiões afro-brasileiras, independentemente das suas modalidades, pois se conformaram a partir de um amálgama de elementos oriundos de diferentes culturas, que podem até parecer conflitantes, mas que animam esse vasto universo dos terreiros de norte a sul do país. No entanto, esse entendimento, apesar de ser encontrado na literatura já há um tempo ${ }^{4}$, não era observado nos processos de patrimonialização de terreiros encampados pelo IPHAN, até pelo menos a primeira metade da década de 2010. Predominava-se a ideia de que os terreiros eleitos como patrimônio nacional eram símbolos vivos de um legado africano no Brasil (MORAIS, 2015).

Os artigos reunidos neste dossiê demonstram que essa postura está sendo, em alguma medida, flexibilizada devido à própria agência das 
comunidades afro-religiosas. Neles o patrimônio é pensado como uma forma de produção cultural no presente que se fundamenta no passado. Mas os produtos do trabalho patrimonial, o que os anglo-saxões chamam de heritage work (PETERSON \& al., 2015), não têm necessariamente os museus como destinação. O patrimônio pode também ser pensado como uma performance e como tal ele expõe a relação com o passado. A exploração das manifestações populares que realçam a referência ao passado (FABRE, 2013) permite assim revelar os espaços de negociação social, através do investimento político dos objetos e das práticas culturais, e sua consequente ressignificação. Para aprendermos esses processos, é importante examinar a capacidade dos atores sociais em se reapropriar dos objetos materiais para se afirmar em uma arena política onde a proximidade de uma origem africana permite confirmar o valor do bem patrimonializado. Os artigos neste dossiê mostram como o povo de santo reivindica uma outra representação das religiões afro-brasileiras no conjunto dos bens patrimonializados, aciona as políticas públicas com vistas a atender seus próprios interesses e ainda cria outras formas de registrar as histórias de suas comunidades.

No primeiro caso, destaca-se o artigo de Stefania Capone (CNRS, CéSor/EHESS) e Mariana Ramos de Morais (CéSor/EHESS), Afro-patrimônio no plural: a mistura no candomblé como valor excepcional. Nele encontramos uma reflexão sobre o processo de patrimonialização das religiões afro-brasileiras, com foco especial no candomblé. Fica evidente no texto a maneira como esse processo é permeado por conflitos e negociações, tanto no nível institucional quanto no religioso. A predominância das casas de matriz jêje-nagô dentre os poucos terreiros alçados a patrimônio nacional levou associações de adeptos de candomblé que reivindicam uma herança cultural banta a questionarem essa hegemonia. Para tanto, esses últimos esforçam-se em cravar à sua representação uma raiz africana "autêntica", lançando-se na busca de uma África banta, ou tentam fazer da "mistura" sua marca distintiva, como foi o caso de um dos últimos terreiros a ser incluído entre os patrimônios nacionais, o Tumba Junsara, em Salvador.

$\mathrm{Na}$ mesma seção do Conselho Consultivo do IPHAN em que foi determinado o tombamento do Tumba Junsara, em 20 de setembro de 2018, outro terreiro foi incluído na lista dos patrimônios nacionais: o Ilê Obá Ogunté, conhecido como Sítio do Pai Adão, em Recife, no estado de Pernambuco. Dos onze terreiros tombados no âmbito nacional, esse é o segundo fora do estado da Bahia e que não pratica o candomblé, como a maioria deles 5 . O Sítio do Pai Adão é um terreiro de xangô. Esse reconhecimento demonstra, assim como no caso do Tumba Junsara, como a mobilização das próprias comunidades está incidindo em uma dada flexibilização da representação das religiões afro-brasileiras no conjunto dos bens patrimonializados pelo IPHAN. Neste dossiê, o artigo O Ilê Obá Ogunté: patrimônio e identidade afro-brasileira, apresentado por Zuleica 
Dantas Pereira Campos (UNICAPE), tem esse processo de patrimonialização como foco. Ao analisá-lo, a autora procura explicitar como os processos de patrimonialização lidam com a religião e com a identidade afro-brasileira no sentido de inserir seus praticantes na história das lutas por legitimidade. Nesse contexto, ela destaca o apoio de representações institucionais, das lideranças religiosas e de militantes de movimentos sociais na reivindicação pelo tombamento do referido terreiro.

Já no artigo Patrimônio festivo, étnico e terapêutico: religiões afro-brasileiras e cultura quilombola, de Fátima Tavares (UFBA), Francesca Bassi (UFRB) e Carlos Caroso (UFBA), fica explícito como as próprias comunidades acionam as políticas públicas com vistas a atender seus interesses. Os autores focalizam um processo de florescimento cultural com algumas iniciativas de patrimonialização mobilizadas por comunidades quilombolas do município de Cachoeira, na Bahia. A cultura afro-religiosa tem especial destaque para uma parcela dessas comunidades, afinando-se a tendências mais amplas de inclusão gradual dos bens culturais das populações minoritárias, ampliando, assim, o escopo dos "bens culturais". Eles apresentam, assim, algumas dessas iniciativas, como a Festa de São Roque e os peditórios da Esmola Cantada; a implantação do turismo étnico de base comunitária da Rota da Liberdade; a revalorização das terapêuticas tradicionais; e a mobilização político-cultural afro-religiosa da Festa da Ostra. Tal como eles demonstram a partir dessas iniciativas, referentes materiais, sensoriais e estéticos afro-religiosos se fazem presentes na fundamentação das "políticas de autenticidade" para a patrimonialização da cultura quilombola.

Outros dois artigos do dossiê focalizam as formas como as próprias comunidades afro-religiosas têm registrado suas histórias. Em Os presentes de Oxum: sentidos da musealização no terreiro do Gantois, Maria Paula Adinolfi (IPHAN/BA) e Mattijs van de Port (Universidade de Amsterdam) centram suas reflexões no caso do Memorial de Mãe Menininha do Gantois, em Salvador, situado no terreiro do Gantois, que foi comandado por Mãe Menininha, uma das mais conhecidas ialorixás da Bahia. No artigo, os autores apontam como os aposentos de Mãe Menininha foram transformados em um local patrimonializado. Eles tomam a história desse memorial para pensar como o museu pode ser entendido como uma "linguagem" específica de status e de prestígio. E, ao fazê-lo, chamam atenção para as mudanças que ocorrem quando novos atores na esfera pública se apropriam dessa linguagem e a transformam. Eles argumentam que, no caso do memorial em questão, apesar do processo de musealização, não houve, de fato, uma diminuição da natureza sagrada do sítio, mas uma nova articulação dessa dimensão.

Saberes escritos, guardados: o acervo documental do Centro Humilde de Caridade São Lázaro, Natal - RN, de Luiz Assunção (UFRN), apresenta o acervo documental produzido pelo babalorixá José Barroso dos Santos, fundador do mencionado terreiro, entre 1960 e 1992. Esse acervo é 
considerado locus da memória do grupo e fonte de conhecimentos e de sua construção identitária. Ele é composto por diferentes documentos, dentre os quais destacam-se: fotografias, livros com descrição das atividades burocráticas e rituais, cadernos com anotações de pontos cantados e ofícios, além de imagens religiosas e objetos ritualísticos. Ao longo do artigo, o autor tece considerações sobre a relação entre a oralidade e a escrita nos processos de transmissão do saber nas comunidades tradicionais de terreiro, bem como sobre a existência e as condições materiais e técnicas para manutenção dos acervos religiosos dessas comunidades. Em relação ao conteúdo do acervo documental, observa duas posturas: uma que se relaciona com a prática religiosa e ritualística, os procedimentos da crença e os cuidados com os praticantes e outra que diz respeito à organização burocrática e administrativa da casa.

Para além da trágica realidade que nos expõe a pandemia de Covid-19, as comunidades afro-religiosas, como já dito neste texto, enfrentam ainda outras adversidades. As políticas públicas que, do início dos anos 2000 até a primeira metade da década de 2010, pareciam dar um suporte para que as comunidades afro-religiosas pudessem dar continuidade às suas práticas - nomeadamente a política cultural, em especial a de patrimônio, e a política racial - não têm recebido do atual governo federal a mesma atenção das gestões anteriores. As pastas encarregadas pelas referidas políticas públicas, por exemplo, perderam seus status de ministério. Soma-se a isso, a crescente influência de grupos evangélicos em arenas como o Congresso Nacional e mesmo no próprio governo federal, que, em muitas ocasiões, empenham-se em impedir o desenvolvimento de ações que contemplam, direta ou indiretamente, essas comunidades. A agência das comunidades afro-religiosas, tal como demonstra este dossiê, é uma ponta de esperança em meio ao preocupante cenário em que vivemos. Resta-nos, portanto, acreditar na capacidade que elas têm de recriar universos rituais, de subverter as ordens vigentes, fazendo surgir outras formas de organização do mundo.

\section{NOTAS}

1. Conforme registrado pela imprensa desde março até 31 de julho, somou-se 92.568 mortes no Brasil por Covid-19. Ver: <https://g1.globo.com/bemestar/ coronavirus/noticia/2020/07/31/casos-e-mortes-por-coronavirus-no-brasil-em-31-de-julho-segundo-consorcio-de-veiculos-de-imprensa.ghtml>. Acesso em: 04 ago. 2020.

2. Para uma análise do processo de tombamento da Casa Branca, ver Velho (2006). 3. A Convenção para Salvaguarda do Patrimônio Cultural Imaterial da Unesco data de 2003. Mas, desde a década de 1970, a necessidade de se incluir a dimensão imaterial dos bens culturais vem sendo debatida por esse organismo internacional. Especialmente, a partir dos anos 1980, o Brasil tem uma participação importante nesse debate. 
4. Para uma análise crítica sobre como foi construída a ideia de uma suposta pureza ritual vinculada a alguns poucos terreiros de tradição iorubá de Salvador (BA), ver Dantas (1988) e Capone (2018 [2004]).

5. Os terreiros de candomblé tombados pelo IPHAN são: Casa Branca (Salvador, Bahia), Axé Opô Afonjá (Salvador, Bahia), Gantois (Salvador, Bahia), Alaketo (Salvador, Bahia), Bate Folha (Salvador, Bahia), Ilê Axé Oxumaré (Salvador, Bahia), Roça do Ventura (Cachoeira, Bahia) e Tumba Junsara (Salvador, Bahia). Constam também dentre os patrimônios nacionais, o terreiro de tambor de mina Casa das Minas (São Luís, Maranhão), o terreiro de culto aos egunguns Omo Ilê Agbôulá (Itaparica (BA) e o terreiro de xangô Sítio Pai Adão (Recife, Pernambuco).

\section{REFERÊNCIAS}

ASSUNÇÃO, Luiz. O Reino dos Mestres: A tradição da jurema na umbanda nordestina. Rio de Janeiro: Pallas, 2006.

CAPONE, Stefania. A busca da África no candomblé: Tradição e poder no Brasil. Segunda edição, revista e ampliada. Rio de Janeiro: Pallas, 2018 [2004]. (Primeira edição francesa: 1999).

CAPONE, Stefania; MORAIS, Mariana Ramos de. De la négation à l'affirmation: le processus d'institutionnalisation du patrimoine culturel afro-brésilien. In: CAPONE, Stefania; MORAIS, Mariana Ramos de (Orgs.). Afro-Patrimoines: culture afro-brésilienne et dynamiques patrimoniales. Paris: Lahic/IIAC/EHESS, 2015. p. 98-18. Disponível em: <http://www.iiac.cnrs.fr/article2813.html>. Acesso em: 20 mai. 2020.

DANTAS, Beatriz Góis. Vovó nagô e papai branco: usos e abusos da África no Brasil. Rio de Janeiro: Graal, 1988.

FABRE, Daniel (Org.). Émotions patrimoniales. Paris: Éditions de la maison des sciences de l'homme, 2013. (Coleção "Ethnologie de la France", Cahier n. 27).

MORAIS, Mariana Ramos de. Les religions afro-brésiliennes en tant que patrimoine: du conflit à l'institutionnalisation. In: CAPONE, Stefania; MORAIS, Mariana Ramos de (Orgs.). Afro-Patrimoines: culture afro-brésilienne et dynamiques patrimoniales. Paris: Lahic/IIAC/EHESS, 2015. p. 98-18.

MORAIS, Mariana Ramos de. De religião a cultura, de cultura a religião: travessias afro-religiosas no espaço público. Belo Horizonte: Editora PUC Minas, 2018.

PETERSON, Derek R.; GAVUA, Kodzo; RASSOOL, Ciraj (Orgs.). The Politics of Heritage in Africa: Economies, Histories, and Infrastructures. Londres/Cambridge: International African Institute \& Cambridge University Press, 2015.

VELHO, Gilberto. Patrimônio, negociação e conflito. Mana, Rio de Janeiro, v. 12, n. 1, p. 237-248, 2006. 